\title{
Accounting for Multiple Intelligences in Interchange Third Edition EFL Course Books
}

\author{
Mahdi Mardani \\ Behbahan Khatam Alanbia University of technology, Behbahn, Iran \\ Mardani.mehdi@gmail.com \\ Habib Soleimani \\ Department of English Language and Literature, University of Kurdistan, Snanadaj, Iran \\ h.soleimani@uok.ac.ir
}

\section{Doi:10.5901/mjss.2016.v7n2s1p244}

\begin{abstract}
The aim of the present study was to analyze Interchange Third Edition English learning course book in light of the Theory of Multiple Intelligences (MI) proposed by Howard Gardner (1983). These series of course books are commonly used in private schools in the Iranian context. The conversations, grammar and reading comprehension activities of the above series were analyzed based on MI checklist prepared and used by Christison et al. (1996) to examine where they included multiple intelligences. The intelligence profile of individual activities of the above mentioned course books were specified and presented. The most common types of intelligences engaged in students in Interchange Third edition were seen to be verbal/linguistic, logical/mathematical, spatial/ visual, interpersonal, and intrapersonal which means engaging five types of intelligences. The results of the study can be applied in the instruction of the mentioned course books to engage MI.
\end{abstract}

Keywords: Content analysis, Interchange Third Edition, Multiple intelligences

\section{Introduction}

Multiple intelligence theory first was developed in 1983 by Gardner. This American psychologist proposed that each individual has different aptitudes and abilities in several subjects and that each person has several kinds of intelligences that are combined differently. In other words, he suggested a theory which defined human intelligence as multiple abilities, including linguistic, musical, logical-mathematical, bodily-kinesthetic, visual-spatial, interpersonal, intrapersonal, and naturalistic.

These eight distinct intelligences "work in concert, not alone, so we are all mixture of multiple intelligences", as Tanner (2001, p. 40) points out. The fact that each person has a unique intelligence profile has substantial implications in education. Tanner lays great emphasis on the notion that "each teacher or learner possesses their own individual intelligence profile, made up of different doses of each type of intelligence" (p.41).

According to Armstrong (1994) the different intelligences are of neutral value. None of the intelligences is superior to the others and each of the mentioned frames is autonomous, changeable and trainable. Gardner (1999) has indicated that the human cognitive ability is not unitary but pluralistic. The traditional curriculum concentrated on verbal and logical intelligences which were thought to be indicators of academic success. Therefore, Gardner (1999) suggested the importance of developing a curriculum that combined different kinds of intelligences, and funded the educational views with role playing, imagination, and storytelling.

Gardner's theory of MI questions the concept of the intelligence quotient (IQ) of Alfred Binet to measure intelligence and prognosticate success in real life. He proposed great concerns about the widespread state of affairs when "important decisions were made on the basis of test scores which were expected to measure intelligence and cognition and were used as a tool of selecting elites" (Gardner, 1993, p. 217). The majority of Binet's successors believed that just as individuals differ in height and weight, or in introversion or integrity, so too they differ from one another in how smart they were (Gardner, 1993). Since then, Binet's method has become a dominant characteristic of the American educational assessment. Tanner in summarizing Gardner's contribution to the study of the human intelligence holds that "Gardner challenges the idea that individuals have a fixed, general, and measurable capacity for learning called intelligence which varies in quantity from person to person" (Tanner, 2001, p. 40).

Since the introduction of MI theory, it has achieved increasing attention in educational circles and has served as a 
framework for curricular designs. Although Gardner's theory has been controversial, it has become a vital force in shaping curricula in many parts of the world and a lot of studies are done in many academic institutions in this regard.

Since the appearance of Ml theory, a number of changes have been made in school curriculums so that authorities can consider the new view of human capacities. Many public and private schools started to base their curriculum upon MI theory after the publication of Gardner's Frames of Mind in 1983 (Weiner, 2001).

The MI theory (Gardner, 1983, 1999, 2004) has significant meaning for education in general, and for language learning in particular (Armstrong, 2007; Azar, 2006; Buchen, 2006; Campbell, L. Campbell, B. \& Dickinson, 2004; Christion, 2004; Duncan \& MaeBaker, 2007; Epelbaum, 2007; Fogarty \& Stoehr, 2007; Tracey \& Richey, 2007; Viens \& Kallenbach, 2004). Richards and Rodgers say that the multiple intelligence model is one of the many learning style models proposed in general education (2003). They quote Campbell who put emphasis on the fact that the multiple intelligence model was not to be taken as a prescription, but rather offering teachers "a complex mental model based on which they would be able to construct curriculum and improve themselves as educators (Campbell, 1997).

Richards and Rodgers have listed a number of new roles of teachers familiarized with Gardner's theory and have shown commitment to it. These teachers "become curriculum developers, lesson designers and analysts, activity founders or inventors, and above all, orchestrators of a rich mix of multisensory activities within the realistic constraints of time, space, and resources of the classroom" (2003, p.120). This method urges teachers to assess their lessons and make them fit every individual learner, keeping in mind his or her unique intelligence profile. This is considered inevitable to ensure learner's full participation in the learning process and guarantee its maximum efficiency (Richards and Rodgers, 2003).

Since FL teaching has changed in order to accommodate learners' needs and potentials, noticeable modifications have also been witnessed in FL textbooks. Textbooks make use of a variety of tasks which combine different methods and approaches so that they reflect the changes in FL teaching. According to a recent research (Snider, 2001, p.1), elements of the Audio-lingual method (ALM), Total physical Response, (TPR) and Communicative Language Teaching (CLT) in a single book showing an eclectic combination of methods, approaches and techniques, have been presented in some textbooks.

Because textbooks have reacted to the changes in FL teaching by mixing differing methods and approaches, MI theory should also be considered in language teaching. Because of the fact that MI theory considers learners' abilities, styles and differences in intelligence profiles, it can contribute greatly to language teaching both in EFL and ESL contexts. The combination of new methods and approaches such as CLT associated with the principles of MI theory would be beneficial for language learners in that they can learn according to their strengths and preferences and they can also develop their less-developed areas while learning a language.

Since textbooks are vital sources for teachers to help students and are the basis of school instruction and the main sources of information for both students and teachers, many researchers have placed emphasis on the importance and the use of textbooks in language teaching (Brown, 2005; Palmberg, 2002; Richards and Rodgers, 2001; Sheldon, 1988).

Hutchinson and Torres (1994) suggest that textbook is considered a universal element of English language instruction and no teaching-learning situation is complete until it has its relevant textbook. Therefore, one of the most important characteristics of good textbooks is paying attention to individual differences and interests of the students. This is very important in motivating the students.

On the other hand, it is observed that those who participate in private language institutes where authentic textbooks such as Interchange and American English file packages are taught are more successful regarding proficiency in English, although other factors and variables are also involved in this success. Changes have also been made in school curriculums in order to consider the new view of human capacities. Many public and private schools started to base their curriculum upon Ml theory and principles after the publication of Gardner's Frames of Mind in 1983 (Weiner, 2001).

Recently some researchers have analyzed textbooks in the light of MI Theory. Palmberg (2002) reports on a study conducted at Abo Akademi University in Finland by a group of student teachers who were participants in an EFL methodology course based on a book entitled "Bricks 1". The results showed that $97 \%$ of the 300 exercises were categorized as verbal/linguistic, 76\% intrapersonal, 25\% interpersonal, $8 \%$ logical/mathematical, 5\% bodily/kinesthetic, 5\% spatial/visual, 3\% naturalist, 2\% musical, and 0\% existentialist. Palmberg (2002) concludes that the textbook intelligence profile which refers to the combination of intelligences in a textbook reflects the writer's personal profile and teachers have the desire to teach according to their learning styles as well as to their own preferences.

In another recent study Kirgoz, (2010) analyzed English Language Teaching textbooks which are locally published in Turkey. The results of this study showed that the intelligence profile of English textbooks was dominantly verbal/linguistic and visual/spatial. 
In an EFL environment like Iran lack of available target language sources sheds lights on the importance of textbooks. For the EFL students, the textbook becomes the major source of contact with foreign language apart from the input suggested by the teacher (Azizifar, Koosha, Lotfi, 2010).

Although many studies have ever been conducted on textbook analysis, none of them has ever analyzed Interchange Third edition in the light of MI theory. Thus, this gap in literature triggered the researcher's motivation to conduct the present study.

Regarding the objectives of the study, the following research question was proposed in the current study:

1. What are the most common Multiple Intelligence types in the Interchange Third Edition series?

\section{Methodology}

The current study employed a survey design in which the researcher analyzed the intended series based on the checklist developed by Christison (1996). Different types of intelligences were found in conversations, grammar, and reading comprehension activities of the series. The process started first with counting the intelligence types of the population and then analyzing and interpreting the results. Content analysis was used to investigate the types of multiple intelligences in Interchange Third Edition. Then the frequencies counted, related percentages calculated, and tables and graphs of each activity type which engaged different intelligences were drawn.

Exercises such as listening, speaking, reading, and writing and also many other activities that exist in Interchange Third edition which work on grammar, vocabulary and pronunciation were used as materials of this study. The passages of these books are mostly authentic, up to date and taken from everyday lives. These series has a student book, a work book, a teacher's book accompanied by audio and video CDs, an interactive CD-ROM and the self-study Audio CD for all four levels. Each Student's Book includes 16 teaching units, and each teaching unit includes 11 to 15 activities which address different skills and components of language. All lessons include different types of activities with a lot of real photos, pictures, and drawings and arts. At the end of all four level course books, there are some interchange activities in which language learners are led to teaching units to provide more pair and group works and speaking activities. There are frequent progress checks after each two units. A self-study section is also available accompanied by some audio CDs. The Workbook follows the same sequence as the Student's Book. Each unit in the Workbook is six pages.

Multiple Intelligences (MI) checklist adapted from Christison (1996), Berman, (1998), and Lazear (1993) were used which comprised the definition of the eight intelligences and a matrix of activities for each kind of the intelligence. For example, a definition for logical-mathematical intelligence involves the ability to use numbers effectively, to engage in higher order thinking, to think in logical patterns, to persuade others in solving problems, and to be able to speak about language itself. Among the activities which are indicators of logical-mathematical intelligence the following can be mentioned: organizing information systematically, note taking, worksheets, listening to lectures, word play games, listening to talking books, reading books, discussions, storytelling, journal keeping, debates, memorizing, writing, applying numbers in relative situations, shapes and patterns, using concretes to understand abstracts, and having the ability of exploring patterns and relationships.

\subsection{Procedures}

Interchange Third edition course books were analyzed to determine to what extent Multiple Intelligence Theory is catered for in these course books and to identify the intelligence profiles related to them. The types of intelligences accounted for, those which were predominant and the less common ones or not included were identified.

In order to spot the intelligences in an activity and assign it to a particular intelligence in conversations, grammar, and reading comprehension activities, the Multiple Intelligence checklists (Berman, 1998; Christison, 1996; Lazear1993) were used.

In analyzing each activity a code was used to identify whether that activity engage certain type of intelligence or not. If it is coded as 1 it means that activity successfully engaged that intelligence. Code zero means intelligence has not been activated by activity.

\subsection{Results}

The analyses of the intelligence profiles of conversations, grammar and reading comprehension activities of Interchange series based on the checklist of this study are shown in the following Tables and Graphs. 


\subsubsection{Conversations}

All conversation activities in Interchange series were coded based on the checklist in order to see whether they engage certain type of intelligence.

According to the checklist of this study, 1376 conversations which engage Ml are shown in Table .1

Table 1. Distribution of MI in Conversation activities of Interchange course books

\begin{tabular}{|c|c|c|c|c|c|c|c|c|c|c|c|}
\hline \multirow{2}{*}{$\begin{array}{l}\text { षे } \\
\text { है } \\
\text { है }\end{array}$} & \multirow{2}{*}{ Type of Intelligence } & \multicolumn{2}{|c|}{ Interchange Intro } & \multicolumn{2}{|c|}{ Interchange 1} & \multicolumn{2}{|c|}{ Interchange 2} & \multicolumn{2}{|c|}{ Interchange 3} & \multicolumn{2}{|c|}{ Total } \\
\hline & & $F$ & $\%$ & $\mathrm{~F}$ & $\%$ & $\mathrm{~F}$ & $\%$ & $\mathrm{~F}$ & $\%$ & $\mathrm{~F}$ & $\%$ \\
\hline 1 & Verbal/Linguistic & 76 & $6 \%$ & 83 & $6 \%$ & 88 & $6 \%$ & 80 & $6 \%$ & 327 & $24 \%$ \\
\hline 2 & Logical/Mathematical & 11 & $1 \%$ & 13 & $1 \%$ & 31 & $2 \%$ & 48 & $3 \%$ & 103 & $7 \%$ \\
\hline 3 & Spatial/Visual & 71 & $5 \%$ & 77 & $6 \%$ & 75 & $5 \%$ & 76 & $6 \%$ & 299 & $22 \%$ \\
\hline 4 & Bodily/Kinesthetic & 16 & $1 \%$ & 15 & $1 \%$ & 19 & $1 \%$ & 13 & $1 \%$ & 63 & $4 \%$ \\
\hline 5 & Musical & 15 & $1 \%$ & 21 & $2 \%$ & 19 & $1 \%$ & 19 & $1 \%$ & 74 & $5 \%$ \\
\hline 6 & Interpersonal & 26 & $2 \%$ & 34 & $2 \%$ & 52 & $4 \%$ & 41 & $3 \%$ & 153 & $11 \%$ \\
\hline 7 & Intrapersonal & 76 & $6 \%$ & 82 & $6 \%$ & 88 & $6 \%$ & 76 & $6 \%$ & 322 & $24 \%$ \\
\hline \multirow[t]{2}{*}{8} & Naturalistic & 14 & $1 \%$ & 9 & $1 \%$ & 5 & $0 \%$ & 7 & $1 \%$ & 35 & $3 \%$ \\
\hline & & 305 & $22 \%$ & 334 & $24 \%$ & 377 & $27 \%$ & 360 & $26 \%$ & 1376 & $100 \%$ \\
\hline
\end{tabular}

As is displayed in Table 1, there are 1376 activities that engage the eight types of intelligences in the conversations of Interchange Third edition package.

This Table shows that verbal/linguistic intelligence is the most common type of intelligence found in $24 \%$ of the activities with the frequency of 327 . That is, in 1376 observations of addressing MI, 327 cases were observed to engage verbal/linguistic intelligence.

The second most frequently addressed type of intelligence is the intrapersonal intelligence with the frequency of 322 and percentage of 24 . The next most observed intelligence in the conversations of Interchange package is spatial/visual which has the percentage of 22.

As we see in Table 4.51, the other types of the intelligences which are addressed in conversation of the series are as follow:

Interpersonal (11\%), logical/mathematical (7\%), musical (5\%), bodily/kinesthetic (4\%), and the least frequent type of intelligence catered for is the naturalistic (3\%) intelligence.

Logical/Mathematical, Bodily/Kinesthetic, Musical, and Natural intelligences are less common and are activated in $18 \%$ of the analyzed activities.

As results of the study reveals here we have the most percentage of all in verbal/linguistics and intrapersonal intelligence then it goes on by engaging all types of intelligences, which is indicative of the fact that series are truly responsive to the theory of multiple intelligences in conversation activities.

\subsubsection{Grammar}

According to the observation of the activities there are 656 cases which address MI in grammar activities of Interchange third edition.

Table 2. Distribution of MI in Grammar activities of Interchange textbooks

\begin{tabular}{|c|c|c|c|c|c|c|c|c|c|c|c|}
\hline \multirow{2}{*}{$\begin{array}{l}\text { ¿ } \\
\text { है } \\
\text { है }\end{array}$} & \multirow{2}{*}{ Type of Intelligence } & \multicolumn{8}{|c|}{ Interchange Intro Interchange 1 Interchange 2 Interchange 3} & \multicolumn{2}{|c|}{ Total } \\
\hline & & $f$ & $\%$ & f. & $\%$ & f & $\%$ & f & $\%$ & $f$ & $\%$ \\
\hline 1 & Verbal/Linguistic & 32 & $5 \%$ & 32 & $5 \%$ & 32 & $5 \%$ & 32 & $5 \%$ & 128 & $20 \%$ \\
\hline 2 & Logical/Mathematica & 32 & $5 \%$ & 32 & $5 \%$ & 32 & $5 \%$ & 32 & $5 \%$ & 128 & $20 \%$ \\
\hline 3 & Spatia & 28 & $4 \%$ & 32 & $5 \%$ & 30 & $4 \%$ & 30 & $5 \%$ & 120 & $18 \%$ \\
\hline 4 & Bodily & 13 & $2 \%$ & 3 & $0 \%$ & 11 & $2 \%$ & 2 & $0 \%$ & 29 & $3 \%$ \\
\hline 5 & Musi & 0 & $0 \%$ & 1 & $0 \%$ & 0 & $0 \%$ & 0 & $0 \%$ & 1 & $0 \%$ \\
\hline 6 & Inter & 32 & $5 \%$ & 32 & $5 \%$ & 32 & $5 \%$ & 32 & $5 \%$ & 128 & $20 \%$ \\
\hline 7 & Intrap & 28 & $4 \%$ & 32 & $5 \%$ & 30 & $5 \%$ & 32 & $5 \%$ & 122 & $19 \%$ \\
\hline 8 & Naturalistic & 0 & $0 \%$ & 0 & $0 \%$ & 0 & $0 \%$ & 0 & $0 \%$ & 0 & $0 \%$ \\
\hline & & 165 & $25 \%$ & 164 & $25 \%$ & 167 & $26 \%$ & 160 & $25 \%$ & 656 & $100 \%$ \\
\hline
\end{tabular}


In analyzing the grammar activities of Interchange third edition package shown in Table 2, it has been revealed that the eight types of intelligences were engaged in 656 cases. We can see in the mentioned Table that $60 \%$ of activities are assumed to engage the verbal/linguistic, logical/mathematical, and interpersonal intelligences. Each type of the above intelligences is seen in $20 \%$ of the activities.

Intrapersonal and spatial/visual intelligences are the next two most frequently catered for intelligences with percentages of 19 and 18 respectively.

The least observed intelligences in the grammar activities of Interchange package are bodily/kinesthetic (3\%) and naturalistic (0\%) intelligences.

\subsubsection{Reading comprehension activities}

With regard to reading comprehension activities there are 308cases which met the objectives of MI checklist regarding inclusion of different kinds of intelligences.

Table 3. Distribution of MI in Reading comprehension activities of Interchange textbooks

\begin{tabular}{|c|c|c|c|c|c|c|c|c|c|c|c|}
\hline \multirow{2}{*}{$\begin{array}{l}\bar{\Phi} \\
\text { E } \\
\text { है }\end{array}$} & \multirow{2}{*}{ Type of Intelligence } & \multicolumn{2}{|c|}{ Interchange Intro } & \multicolumn{2}{|c|}{ Interchange 1} & \multicolumn{2}{|c|}{ Interchange 2} & \multicolumn{2}{|c|}{ Interchange 3} & \multicolumn{2}{|c|}{ Total } \\
\hline & & $f$ & $\%$ & $\mathrm{~F}$ & $\%$ & $\mathrm{~F}$ & $\%$ & $f$ & $\%$ & $f$ & $\%$ \\
\hline 1 & Verbal/Linguistic & 12 & $4 \%$ & 16 & $5 \%$ & 16 & $5 \%$ & 16 & $5 \%$ & 60 & $19 \%$ \\
\hline 2 & Logical/Mathematical & 10 & $3 \%$ & 6 & $2 \%$ & 16 & $5 \%$ & 15 & $5 \%$ & 47 & $15 \%$ \\
\hline 3 & Spatial/Visual & 12 & $4 \%$ & 15 & $5 \%$ & 15 & $5 \%$ & 16 & $5 \%$ & 58 & $19 \%$ \\
\hline 4 & Bodily/Kinesthetic & 5 & $2 \%$ & 0 & $0 \%$ & 0 & $0 \%$ & 0 & $0 \%$ & 5 & $2 \%$ \\
\hline 5 & Musical & 2 & $1 \%$ & 1 & $0 \%$ & 1 & $0 \%$ & 0 & $0 \%$ & 4 & $1 \%$ \\
\hline 6 & Interpersonal & 12 & $4 \%$ & 16 & $5 \%$ & 16 & $5 \%$ & 16 & $5 \%$ & 60 & $19 \%$ \\
\hline 7 & Intrapersonal & 12 & $4 \%$ & 16 & $5 \%$ & 16 & $5 \%$ & 16 & $5 \%$ & 60 & $19 \%$ \\
\hline 8 & Naturalistic & 7 & $2 \%$ & 2 & $1 \%$ & 4 & $1 \%$ & 1 & $0 \%$ & 14 & $4 \%$ \\
\hline & & 72 & $24 \%$ & 72 & $23 \%$ & 84 & $26 \%$ & 80 & $25 \%$ & 308 & $100 \%$ \\
\hline
\end{tabular}

Table 3 is the result of analyzing Interchange third edition package for identifying different types of $\mathrm{Ml}$ in the reading activities.

Different types of MI have been observed to have been involved in 308 activities. Each of the verbal/linguistic, spatial/visual, interpersonal, and intrapersonal was addressed with the distribution of $19 \%$. That is, about $76 \%$ of the activities only involved these four types of intelligences.

Logical/mathematical intelligence takes the second place in being catered for in the activities with $15 \%$.

The least frequently addressed intelligences are naturalistic (4\%), and bodily/kinesthetic (2\%) in the reading activities of Interchange package.

Analysis of the findings indicated that there are more varieties in the amount and qualities of the activities which have been developed for this package. It seems that the material developers of this package are aware of the Multiple Intelligences theory and the effects that it has on the curriculum development and syllabus design of instructional materials.

\section{The Intelligence Profile for the Interchange Third Edition Series as a Whole}

MI was engaged in 2340 activities of Interchange third edition series. Tables 4 and 5 and Graph 1 indicate the results of the analysis for the intelligence profiles in conversations, grammar and reading comprehension activities of the mentioned textbooks.

Table 4. Frequency of Distribution of MI in each of the Interchange third edition series

\begin{tabular}{lccccccccc}
\hline Textbook & V/L & L/M & S/V & B/K & M. & Inter. & Intra. & Nat. & Total \\
Interchange Intro & 120 & 53 & 111 & 34 & 17 & 70 & 116 & 21 & 542 \\
Interchange 1 & 131 & 51 & 124 & 18 & 23 & 82 & 130 & 11 & 570 \\
Interchange 2 & 136 & 79 & 120 & 30 & 20 & 100 & 134 & 9 & 628 \\
Interchange 3 & 128 & 95 & 122 & 15 & 19 & 89 & 124 & 8 & 600 \\
Total & 515 & 278 & 477 & 97 & 79 & 341 & 504 & 49 & 2340 \\
\hline
\end{tabular}


Table 5. Distribution of MI in Interchange third edition series

\begin{tabular}{cccccccccc}
\hline Intelligence & $\mathrm{V} / \mathrm{L}$ & $\mathrm{L} / \mathrm{M}$ & $\mathrm{S} / \mathrm{V}$ & $\mathrm{B} / \mathrm{K}$ & Mus. & Inter. & Intra. & Nat. & Total \\
& 515 & 278 & 477 & 97 & 79 & 341 & 504 & 49 & 2340 \\
& $22 \%$ & $11 \%$ & $20 \%$ & $04 \%$ & $03 \%$ & $14 \%$ & $21 \%$ & $02 \%$ & $100 \%$ \\
\hline
\end{tabular}

Graph 1. Distribution of MI in Interchange third edition series

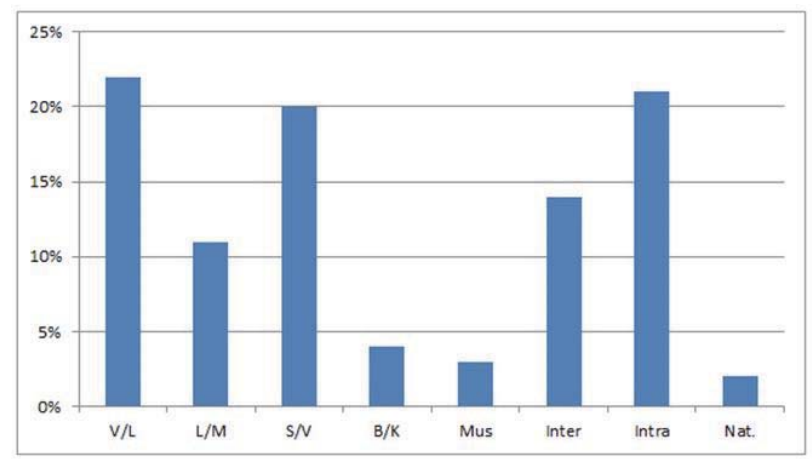

\section{Conclusion}

The current study was conducted to shed light on different types of intelligences employed by different activities in Interchange third edition series.

There are 515 Conversation, Grammar, and Reading comprehension activities in Interchange package which engaged Multiple Intelligences in 2340 cases. The findings revealed that the intelligence profiles for this package are Verbal/Linguistic, Logical/Mathematical, Spatial/Visual, Intrapersonal, and Interpersonal and these types of intelligences were engaged by $91 \%$ of the activities and the other three types of intelligences were catered for in just $9 \%$ of the activities.

As we analyzed the activities, it was noticed that these series are really responsive to the theory of Multiple Intelligences. Although, the series start by engaging all types of Multiple Intelligences, the first two levels only include four types of intelligences. However, in the last two levels both the number of activities and intelligences engaged increase in number and the intelligence profile increases to five of the intelligences and the other three intelligences are not ignored too.

Furthermore, analysis of the findings indicated that there are lots of varieties in the amount and qualities of the activities which have been developed for this package. It seems that the material developers of this package are aware of the Multiple Intelligences theory and the effects that it has on the curriculum development and syllabus design of instructional materials.

Examining the above Tables and Graphs is indicative of the fact that the frequencies of distribution and the related percentages for verbal/linguistic intelligence, intrapersonal, spatial/visual, Interpersonal, are 515 (22\%), 504 (21\%), $477(20 \%)$, and $341(14 \%)$ respectively, which is indicative of the fact that the activities which engage these types of Intelligences have been distributed very well through the books.

The case for the logical/mathematical, bodily/kinesthetic, naturalistic, musical intelligences activities in Interchange package is somehow different. In fact number of activities supporting MI in the case of these activities is not enough in these series.

In conclusion the Interchange Third edition package caters for multiple intelligences in a good way so that the intelligence profiles for these textbooks are verbal/linguistic, logical/mathematical, spatial/visual, intrapersonal, and interpersonal. The other three types of intelligences are not ignored and there are activities which activate them. However, the amount of those activities is not comparable to the other five intelligences.

In a nutshell, the use of textbooks which address $\mathrm{MI}$ in schools help educators have their teaching beyond linguistic and logical-mathematical intelligences which leave many students out of the learning process. MI supported materials is a help for educators to understand cognitive abilities and be responsive to other types of intelligence. 


\section{References}

Armstrong, T. (1994). Multiple Intelligences in the Classroom. Virginia ASCD.

Armstrong, T. (2007).The curriculum superhighway. Educational Leadership, 64(8), 16- 20.

Azar, A. (2006). Relationship of multiple intelligences profiles with area of constitution in high school and university entrance exam scores. Educational Administration: Theory \& Practice, 46, 157-174.

Azizifar. A., Koosha.M., and Lotfi.A. (2011). An Analytical Evaluation of Iranian High School ELT Textbooks from 1970 to the Present. .Asian TEFL, 8(1).1-162.

Brown, C. L. (2005). Ways to help ELLS: ESL teachers as consultants. Academic Exchange Quarterly, 9(4), 255-261.

Berman, M. (1998). A Multiple Intelligences Road To An ELT Classroom. Wales, UK: Crown House Publishing Limited.

Buchen, I. H. (2006). Futures thinking, learning, and leading: Applying multiple intelligences to success and innovation. Lanham, MD: Rowman\& Littlefield Education.

Campbell, L., Campbell, B. \& Dickinson, D. (2004).Teaching and learning through multiple intelligences. Chicago, IL: Merill Company.

Christison, M.A. (1996). Teaching and Learning Languages Through Multiple Intelligences. TESOL Journal, 6(1), 10-14.

Duncan, J., \&MaeBaker, C. (2007). Teaching to multiple intelligences. Journal for Global Business Education, 7, 21-35.

Epelbaum, D. (2007). Multiple intelligences assessment gives insight into reading comprehension difficulties and potential: A case study. International Journal of Learning, 14(5), 243-251.

Fogarty, R., \& Stoehr, J. (2007).Integrating the curricula with multiple intelligences: Teams, themes, and threads (2nd. ed.). Thousand Oaks, CA: Corwin-Sage Press.

Gardner, H. (1993). Multiple intelligences: The theory in practice. New York: Basic Books.

Gardner, H. (1983). Frames of mind. New York: Basic books Irma, K. (1996). Whole Language EFL with Styles Adapting Traditional Texts to Diverse Learning Styles and Intelligences. (ERIC, Document Reproduction Service, ED 400717.

Gardner, H. (1999). Intelligence Reframed: Multiple Intelligences for the 21st Century. New York: Basic Books.

Hutchinson, T \& Torres, D. (1994). The textbook as agent of change. ELT Journal, 48, 315-328.

Kirgoz, Y. (2010). Catering for multiple intelligences in locally-published ELT textbooks in Turkey. Procedia Social and Behavioral Sciences (3), 127-130. Retrieved April 2, 2012, from the Sciencedirect.

Lazear, D. (2004). Higher-order thinking the multiple intelligences way. Saint Paul, MN: Zephyr Press.

Palmberg, R.(2002). Catering for Multiple Intelligences in EFL coursebooks. Humanising Language Teaching ( 4)1.

Richards, J. \& Rodgers, T. (2001).Approaches and methods in language teaching. Second Edition. Cambridge: CUP.

Richards, J. C., Rodgers, T. S.(2003). Approaches and Methods in Language Teaching. Cambridge University Press, second edition, 2003.

Sheldon, L.E. (1988). Evaluating ELT textbooks and materials. ELT Journal, 42,4,237- 246.

Tanner, R. (2001). Teaching intelligently. English Teaching professional,20 pp. 40-41.

Snider, D. P. (2001). Multiple Intelligences Theory and Foreign Language Teaching. Unpublished doctoral dissertation, University of Utah. Retrieved on July, 2012.

Tracey, M., \& Richey, R. (2007). ID model construction and validation: A multiple intelligences case. Educational Technology Research \& Development, 55(4), 369-390.

Viens, J., \&Kallenbach, S. (2004). Multiple intelligences and adult literacy: A Source book for practitioners. New York: Teachers College Press.

Weiner, A.G. (2001). Investigating commonalities among elementary schools that have implemented the theory of multiple intelligences: A guideline for the 21st century. Unpublished doctoral dissertation, Lehigh University. 